\title{
Safeguarding a global seed heritage from Syria to Svalbard
}

\author{
Ola T. Westengen ${ }^{1 凶}$, Charlotte Lusty ${ }^{2}$, Mariana Yazbek $^{3}$, Ahmed Amri ${ }^{4}$ and Åsmund Asdal ${ }^{5}$
}

\begin{abstract}
Crop diversity underpins food security and adaptation to climate change. Concerted conservation efforts are needed to maintain and make this diversity available to plant scientists, breeders and farmers. Here we present the story of the rescue and reconstitution of the unique seed collection held in the international genebank of International Center for Agricultural Research in the Dry Areas (ICARDA) in Syria. Being among the first depositors to the Svalbard Global Seed Vault, ICARDA managed to safety duplicate more than $\mathbf{8 0} \%$ of its collection before the last staff had to leave the genebank in 2014 because of the war. Based on the safety duplicates, ICARDA since $\mathbf{2 0 1 5}$ have rebuilt their collections and resumed distribution of seeds to users internationally from their new premises in Morocco and Lebanon. We describe the multifaceted and layered structure of the global system for the conservation and use of crop diversity that enabled this successful outcome. Genebanks do not work alone but in an increasingly strengthened and experienced multilateral system of governance, science, financial support and collaboration. This system underpins efforts to build sustainable and socially equitable agri-food systems.
\end{abstract}

In September 2015, staff from the Syrian genebank at the International Center for Agricultural Research in the Dry Areas (ICARDA) came to the arctic island Svalbard to retrieve seeds from the Svalbard Global Seed Vault. The seeds retrieved were safety duplicates of the invaluable seed collection held in ICARDA's genebank at Tel Hadia, $33 \mathrm{~km}$ south of Aleppo, the staff of which by then had been forced to leave because of the war.

The seeds at risk in this rescue operation represent some of the most precious biodiversity to humanity on the planet ${ }^{1,2}$. Genebanks such as ICARDAs are so-called ex situ (outside their natural habitats) conservation facilities for crop diversity, or to use the technical term, Plant Genetic Resources for Food and Agriculture (PGRFA) seeds, plants and plant parts useful in crop breeding, research or conservation for their genetic attributes ${ }^{3}$. This term directs attention to the economic importance of this biodiversity, which underpins not only all current plant-based food production but also the necessary efforts to build healthier and more environmentally sustainable food systems for the future ${ }^{4,5}$. This biodiversity has shaped human societies and cultures for millennia, enabling the growth of sophisticated cities and feeding the expansion of empires ${ }^{6-8}$. The ICARDA genebank is particularly important in this regard as it harbours the largest collection of crop diversity from the earliest centre of origin of agriculture, the Fertile Crescent ${ }^{9,10}$. The Syrian war comes on top of a suite of threats to crop diversity grown in farmers' fields; this loss of diversity has been recognized for more than 50 years ${ }^{1,11}$. The gravity of the threat to such essential biodiversity is addressed in conservation goals of international agreements, including the Convention on Biological Diversity $(\mathrm{CBD})^{12}$, the International Treaty on Plant Genetic Resources for Food and Agriculture (Plant Treaty) ${ }^{13}$ and the Sustainable Development Goals (SDGs) ${ }^{14}$.

The ICARDA collections include thousands of traditional landraces and wild relatives of staple food crops representing unique diversity, some of which are probably no longer found in the field ${ }^{15}$. The genebank is important not only for agriculture in the Middle East but for global food production and food security. Since its establishment in 1976, the research centre has worked in more than
50 countries with temperate dryland agriculture, focusing on a range of cropping systems involving barley, lentil and faba bean on a global scale as well as wheat, chickpea and grasspea in regional programmes. The seed accessions are available free of charge to plant breeders, researchers and other users under the terms and conditions of the Plant Treaty. Access to this diversity is crucial, as evident from the enormous importance of these crops for global food security today ${ }^{16}$ and from the paramount importance crop diversity and plant breeding has for adaptation to climate change ${ }^{17,18}$.

The ICARDA genebank was among the first depositors when the Svalbard Global Seed Vault opened in 2008. The research centre continued to send seeds for safety duplication to Svalbard when the war broke out, and had managed to safety duplicate more than $80 \%$ of its unique seed collection by the time of its last deposit in 2014 . ICARDA staff started to retrieve seeds in 2015 when the war made it impossible to continue operation of the Tel Hadia genebank, and it was decided that all genetic resources conservation activities were to be relocated to Lebanon and Morocco where new genebank facilities were established. The retrieved seed samples have since been multiplied up in large numbers to produce fresh seed for reconstruction of active and base collections as well as for distribution. The regenerated accessions are now available for users around the world, and fresh safety duplicates have been returned to Svalbard for long-term back-up.

The situation in Syria illustrates well the inextricable but complex links between climate change, food security and sociopolitical stability in fragile states. A series of droughts during 2006-2009 linked to climate change probably played a role in the uprising in Syria in 2011 (refs. ${ }^{19,20}$ ). It is clear that climate change-induced droughts alone do not account for the Syrian tragedy, but rather was one ingredient in a concoction of social, economic and political factors which together triggered the events that escalated into civil war $^{21,22}$. The war has further aggravated food insecurity and climate change vulnerability in the country ${ }^{23,24}$. Farmers have, in some seasons and areas, not been able to produce; supply chains have broken down; and control and sabotage of farms and food supply have been

'Department of International Environment and Development Studies, Norwegian University of Life Sciences, Aas, Norway. ${ }^{2} \mathrm{Global}$ Crop Diversity Trust, Bonn, Germany. ${ }^{3}$ CARDA, Beirut, Lebanon. ${ }^{4}$ ICARDA, Rabat, Morocco. ${ }^{5}$ NordGen, Alnarp, Sweden. ${ }^{凶}$ e-mail: ola.westengen@nmbu.no 


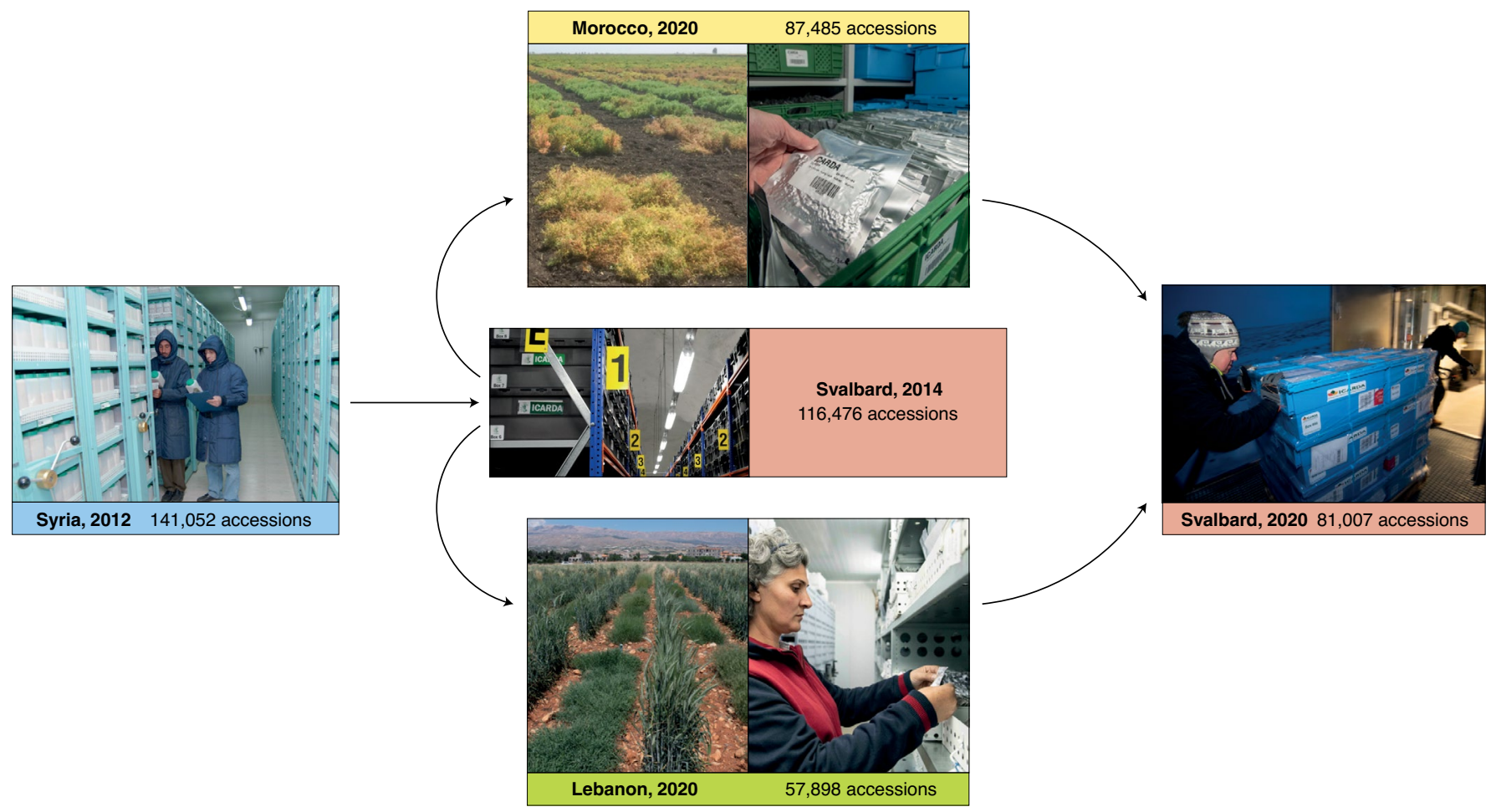

Fig. 1 | Diagram of accession 'flow' from Syria-Svalbard-Morocco/Lebanon-Svalbard. By September 2020, all the safety duplicates stored in the Seed Vault by 2014 had been regenerated and multiplied by ICARDA in Morocco and Lebanon. In addition, accessions emergency safety duplicated in Turkey and new accessions are included in the ICARDA collections in Morocco and Lebanon. A total of 81,007 new safety duplicates have been stored in the Seed Vault as of September 2020. Images adapted from the Global Crop Diversity Trust.

used as weapons in the war ${ }^{25}$. Improving the food security situation will be crucial in efforts to restore peace and political stability in the country, and, in these efforts, national and international agricultural research institutions like ICARDA will play a key role in developing and disseminating well-adapted crop varieties.

In retelling the story of the safety duplication, retrieval and reconstruction of the ICARDA collection, it becomes clear that there are many interrelated elements contributing to what has been effectively a successful outcome. We describe the multifaceted and layered structure of the global system for the conservation and use of PGRFA. The institutional architecture of the global system aside from ICARDA and the Seed Vault include financing structures and implementing institutes at the national and international level. These institutes are connected through standards of operation and practice, legal agreements, data portals and data management tools, decades of partnership, funding and more. Underpinning all of this lies the Plant Treaty. While parts of this story have been described in the popular media and presented in various policy fora by the researchers and institutions involved, this Perspective accurately documents and analyses this historical event. The event provides a unique source of insights into what a resilient ex situ conservation system entails in terms of technical, institutional and policy factors.

This Perspective presents first-hand observations and original data from the organizations and people involved. All the authors have played a direct role in the events described. The data presented are from germplasm databases managed by ICARDA, NordGen, the Food and Agriculture Organization (FAO) and the Crop Trust, from the regeneration results from ICARDA's field stations in Morocco and Lebanon as well as complementary information from media reports, United Nations (UN) reports and the research literature. The Perspective will be structured as follows: first, we present the story of the safety duplication and retrieval of the ICARDA collection at Svalbard; second, we provide an overview of the existing global ex situ conservation system for PGRFA and define the role of the ICARDA genebank and the Seed Vault within this system; third, we discuss technical as well as institutional and policy lessons learned from the rebuilding of the ICARDA collections; and finally, we conclude with a discussion of how a functioning global ex situ conservation system is key for researchers, farmers and other actors involved in building more sustainable and equitable agri-food systems.

\section{Saving the ICARDA collection}

When the war broke out in Syria in March 2011, ICARDA had already safety duplicated more than 100,000 accessions at Svalbard. Continuing their work during the warfare, the ICARDA genebank staff managed to prepare and ship an additional 14,363 accessions via three shipments in 2012, 2013 and 2014 (Fig. 1). The shipments to Svalbard were timed according to the security situation in Aleppo, and NordGen organized extraordinary openings of the Seed Vault to accommodate this. The last deposit was sent from Aleppo in January 2014. When the last staff were forced to leave Tel Hadia later in 2014, the total number of safety duplicates at Svalbard was 116,476 samples, or $83 \%$ of all accessions stored in the genebank at the time of the outbreak of the war. In addition, 13,939 accessions that were not safety duplicated in Svalbard or any other genebank were sent to Turkey as emergency 'black box' safety duplicates. In spite of the war and ICARDA staff being located in multiple countries, genebank activities and germplasm distribution continued. The deposits were kept away from the media until ICARDA chose to go public about the operation in April 2014, after the last deposit had been made.

The courageous efforts of the ICARDA staff who continued to manage the collection and prepare and ship safety duplicates out of Syria even as the war ravaged outside the genebank have been praised in international media reports ${ }^{26}$, and in 2015, such efforts earned them an award from the Gregor Mendel Foundation ${ }^{27}$. 
These efforts by the local staff of the Genetic Resources Section (GRS) team at Tel Hadia during this period will be remembered in the history of genebanking together with the history of the staff of the Vavilov Institute of Plant Industry (VIR), who safeguarded the famous genebank during the Nazi siege of Leningrad in the winter of 1941-1942 (ref. ${ }^{28}$ ).

When access to the Tel Hadia genebank was definitively closed down in September 2015, the reallocated ICARDA staff in Lebanon and Morocco contacted the NordGen staff and made arrangements for retrieving the safety duplicate boxes in batches over a number of years. When the boxes reached the ICARDA premises in Lebanon and Morocco, the enormous work of regeneration and multiplication of the samples started. More than 30,000 samples have been regenerated annually since 2016 . The regenerated accessions are multiplied to the point where enough good quality seed is available for long-term storage, medium-term storage and safety duplication in two locations. By the end of the regeneration season in 2019, 83,702 accessions were already available to the users of the ICARDA collection. At the same time as seeds are made available for distribution, new safety duplicate boxes are prepared and returned to the Seed Vault.

\section{The global ex situ conservation system anno 2020}

The Seed Vault is the ultimate back-up storage for the world's crop diversity and thus part of the international efforts towards the SDGs. SDG 2.5 says the world should "by 2020 , maintain the genetic diversity of seeds, cultivated plants and farmed and domesticated animals and their related wild species, including through soundly managed and diversified seed and plant banks at the national, regional and international levels, and promote access to and fair and equitable sharing of benefits arising from the utilization of genetic resources and associated traditional knowledge, as internationally agreed"14. The indicator for measuring progress towards SDG 2.5 is a simple count of "the number of plant and animal genetic resources for food and agriculture secured in either medium or long-term conservation facilities" 29 . According to the FAO, the global holdings of PGRFA conserved in genebanks in 99 countries and 17 regional and international centres totalled 5.3 million samples at the end of 2018 (ref. ${ }^{29}$ ). While this is a high number, the conservation target is not achieved. At the beginning of 2020, the year SDG 2.5 should have been met, FAO reported that the conservation status of genetic resources of both plants and animals was "off-track" to meet the target $^{29}$. Furthermore, while we know what is collected and stored in genebanks, we do not have a satisfactory overview of what is missing from these collections. In the State of the World's Biodiversity for Food and Agriculture, the FAO reported that the current situation is characterized by 'decreasing plant diversity in farmers' fields" ${ }^{\prime 3}$. This is a dire status for biodiversity of such vital importance for human wellbeing and resilience. In recognition of the need to remedy this situation, a number of international agreements and projects from the global to the local level aimed at governing and managing PGRFA now exist.

The Plant Treaty is the most directly relevant and important international biodiversity agreement pertaining to governance of PGRFA. Currently this international treaty is signed by 146 parties (including the European Union) ${ }^{31}$. The Plant Treaty came into force in 2004 and was negotiated in recognition of the need to develop a legally binding agreement for governing PGRFA at a time when two other binding agreements had been established: the CBD in 1992, for governing all biodiversity, and the World Trade Organization Trade-Related Aspects of Intellectual Property Rights in 1994, with its direct implications for governance of new plant varieties ${ }^{32,33}$. The uniqueness of PGRFA with regards to the global interdependence of this part of the planet's biodiversity was an important background for the negotiation of a dedicated international agreement ${ }^{3,16}$, and in the 'Nairobi Final Act' of the CBD, a resolution recognized the need
Table 1 | Key performance indicators for the genebanks in the CGIAR Genebank Platform

\section{Indicator} Target

Availability

Ninety percent of accessions

Percentage of collection that is clean of pathogens of quarantine risk, viable and in sufficient quantity to be immediately available for international distribution from medium-term storage.

\section{Safety duplication}

For seed crops: percentage of collection held in long-term storage at two locations and also in Svalbard Global Seed Vault (except for tree spp.).

For clonal crops: percentage of collection held in long-term storage or cryopreservation at two locations or in slow growth conditions in vitro at two locations.

\section{Data availability}

Entire collection with minimum passport and/or characterization data online.

\section{QMS}

QMS in place.

Ninety percent of accessions safety duplicated

Ninety percent of accessions duplicated in in vitro or cryopreservation.

Passport Data Completeness Index (PDCl) greater than six.

Agreed minimum elements of ISO for QMS are in place: validated SOPs, restricted access, barcoding, staff succession plan and risk management plan.

QMS, quality management system; ISO, International Organization for Standardization.

for solutions to two outstanding matters concerning PGRFA: access to ex situ collections acquired prior to the CBD, and the question of farmers' rights ${ }^{33}$. The outcome of the ensuing negotiation in FAO was thus the Plant Treaty, with the following threefold objective in harmony with the objective of the CBD: "the conservation and sustainable use of all plant genetic resources for food and agriculture and the fair and equitable sharing of the benefits arising out of their use, in harmony with the Convention on Biological Diversity, for sustainable agriculture and food security"13. Among the important features of the Plant Treaty are the provisions for conservation and sustainable use, the recognition of farmers' rights and the multilateral system (MLS) for access and benefit-sharing (ABS). Through the MLS, the Plant Treaty's member countries commit to provide 'facilitated access' to genetic resources of 35 specified food crops and 29 forages. A number of other crops were initially proposed, but many were excluded from the MLS genepool by governments during the negotiation ${ }^{3,32}$. The terms and conditions for ABS are laid out in a Standard Material Transfer Agreement (SMTA) that shall be used for all germplasm exchange in the MLS. While the CBD and its Nagoya Protocol require mutually agreed terms of access and benefit-sharing between providers and users of genetic resources, the SMTA of the Plant Treaty is a standard, non-negotiable agreement between providers and users of the MLS plant materials. The SMTA states that monetary benefits that arise from the use of the MLS materials are shared through the Benefit Sharing Fund (BSF) administered by the Plant Treaty's Secretariat at the FAO. The BSF primarily supports on-farm management and conservation projects in developing countries, and since 2009 has funded more than 80 projects through four cycles of competitive grant schemes ${ }^{31,34}$. While the BSF prioritizes in situ and on-farm management of genetic resources, funding for ex situ management is the mandate of the Crop Trust - an international organization recognized by the Governing Body of the Plant Treaty as an essential element of the treaty's funding strategy ${ }^{34}$. 
The Plant Treaty and the CBD are thus the legal frameworks that together constitute the governance regime for PGRFA. A virtual overview of the PGRFA in this system is provided by a Global Information System (GLIS) ${ }^{31}$. Part of the GLIS is an online portal for accession-level information called Genesys, which has data on more than four million accessions from 33 data providers, including both the European and United States' networks of genebanks ${ }^{35}$. When accessing information about a particular accession in Genesys, users can find out if it is available as part of the MLS and whether it is safety duplicated in the Svalbard Global Seed Vault. Another entry point to information is the seed portal website, which by September 2020 reported a holding of more than one million safety duplicates from 88 genebanks in the Seed Vault ${ }^{36}$.

According to Genesys, the 11 genebanks of the CGIAR network of international agricultural research centres manage more than 770,000 accessions of crop, tree and forage diversity ${ }^{37,38}$. CGIAR genebanks are among a small number of international collections that stand out because they are not under the jurisdiction of the individual Contracting Parties to the Plant Treaty but are held 'in-trust' for the global community through a dedicated article (Article 15) in the Plant Treaty. Each CGIAR genebank has responsibility for specific staple crops of global significance. The genebanks under Article 15 and those "in the public domain and under the control of the parties" ${ }^{13}$ hold the physical resources of the MLS. According to the State of the World's PGRFA from 2010, there are as many as 1,750 genebanks around the world ${ }^{39}$. Most of them are public genebanks managed under national agricultural research organizations (NAROs) or academic institutions. In addition, there are some genebanks managed by non-governmental organizations, and there are a number of private genebanks owned by seed companies. The majority of these private genebanks are yet to include their plant materials in the MLS, and their collections are thus not available for facilitated access and benefit-sharing. Furthermore, many of the genebanks included in the FAO's database struggle to obtain adequate funding and capacity to maintain the viability of the genetic resources they conserve ${ }^{39}$; thus, genetic erosion is happening not only in the field, but most likely also inside the very facilities constructed to conserve them.

In addition to the Plant Treaty, genebanks also operate in relation to other international and national laws and regulations. Plant health regulations put in place measures for controlling and managing pests and diseases, and at a national and regional level conform to the internationally agreed standards of the International Plant Protection Convention (IPPC). The IPPC Secretariat is housed in the FAO, and so is the Commission on Genetic Resources for Food and Agriculture (CGRFA), which is an intergovernmental body dealing with genetic resources policies and guidelines in general. The Genebank Standards ${ }^{40}$ developed under the guidance of the CGRFA is an important technical reference for the global ex situ conservation system.

The operations and activities of the CGIAR genebanks are managed under the CGIAR Genebank Platform, which features a monitoring system and comprehensive quality management system (QMS) based on the FAO genebank standards, IPPC standards and Plant Treaty framework ${ }^{41}$. The Genebank Platform, unusually for a CGIAR programme, is not led by a CGIAR centre but by an independent organization, the Crop Trust, which has the sole mission of supporting the conservation and availability of crop diversity for food security worldwide. The Crop Trust does this primarily through raising money for an endowment fund designed to financially sustain the most important global collections of crop diversity in perpetuity. Given this objective, the Crop Trust has been working with CGIAR genebanks and other international and national genebanks to strengthen the status of collections under their management. The ultimate aim is to reach four performance targets (Table 1) related to the availability, safety duplication, documentation and management of the collections.
Table 2 | The PGRFA holdings in the ICARDA genebank in Syria in July 2012 and in Morocco and Lebanon by April 2020

\begin{tabular}{|lll|}
\hline Crop taxa & $\begin{array}{l}\text { Unique accessions } \\
\text { held in Syria up to } \\
\text { June 2012 }\end{array}$ & $\begin{array}{l}\text { Unique accessions held } \\
\text { in Lebanon and Morocco } \\
\text { by April 2020 }\end{array}$ \\
\hline Faba bean & 9,542 & 8,745 \\
\hline Aegilops & 4,058 & 4,464 \\
\hline Barley & 28,321 & 30,060 \\
\hline Bread wheat & 14,101 & 15,023 \\
\hline Durum wheat & 19,640 & 19,896 \\
\hline Primitive wheat & 912 & 1,494 \\
\hline Wild Hordeum & 1,989 & 2,146 \\
\hline Wild Triticum & 1,579 & 2,194 \\
\hline Lathyrus & 3,993 & 4,014 \\
\hline Medicago & 8,413 & 7,628 \\
\hline Range and pasture & 5,860 & 5,773 \\
\hline Pisum & 6,106 & 4,180 \\
\hline Trifolium & 4,584 & 5,478 \\
\hline Vicia & 6,147 & 5,736 \\
\hline Chickpea & 14,214 & 13,222 \\
\hline Lentil & 10,496 & 13,467 \\
\hline Wild Cicer & 271 & 479 \\
\hline Wild Lens & 587 & 623 \\
\hline Others & 239 & 285 \\
\hline Total & $\mathbf{1 4 1 , 0 5 2}$ & $\mathbf{1 4 4 , 9 0 7}$ \\
\hline
\end{tabular}

CGIAR genebanks, especially since 2012, have striven to improve the status of their collections with respect to the performance targets and the efficiency of operations, as well as to modernize the facilities in which the collections are held ${ }^{38}$. Accession documentation is monitored using the Passport Data Completeness Index ${ }^{42}$. As part of the QMS, individual genebanks' operations are documented in detail in standard operating procedures, which are audited and validated through external expert review. An increasing number of genebanks are adopting and further developing a data management software, GRIN-Global, which facilitates the sharing of best practice, data and software developments as well as the upload of regular updates to Genesys ${ }^{43}$.

\section{The ICARDA genebank}

The ICARDA genebank is one of the Article 15 collections and a member of the CGIAR Genebank Platform. ICARDA has a regional and international mandate for a number of key food security crops, as reflected in the holdings of different taxa (Table 2). Out of the approximately 157,000 accessions, 58\% are landraces and crop wild relatives, $20 \%$ are forages and range species, and the remainder are breeding lines at various stages as well as released varieties. The material originated from farmers' fields and wild habitats from locations around the world, but the majority are from Central and West Asia and North Africa, representing four major centres of diversity (the Mediterranean region, the Abyssinian region, West Asia and Central Asia), and thus the Fertile Crescent ${ }^{15}$. ICARDA has always managed an active genebank with relatively high germplasm distribution rates and published research on novel approaches such as Focused Identification of Germplasm Strategy (FIGS) ${ }^{44}$, which contribute to building demand for accessions and diversity. The uniqueness and value of this collection is reflected in the demand for germplasm and collaboration. Germplasm distribution from the 


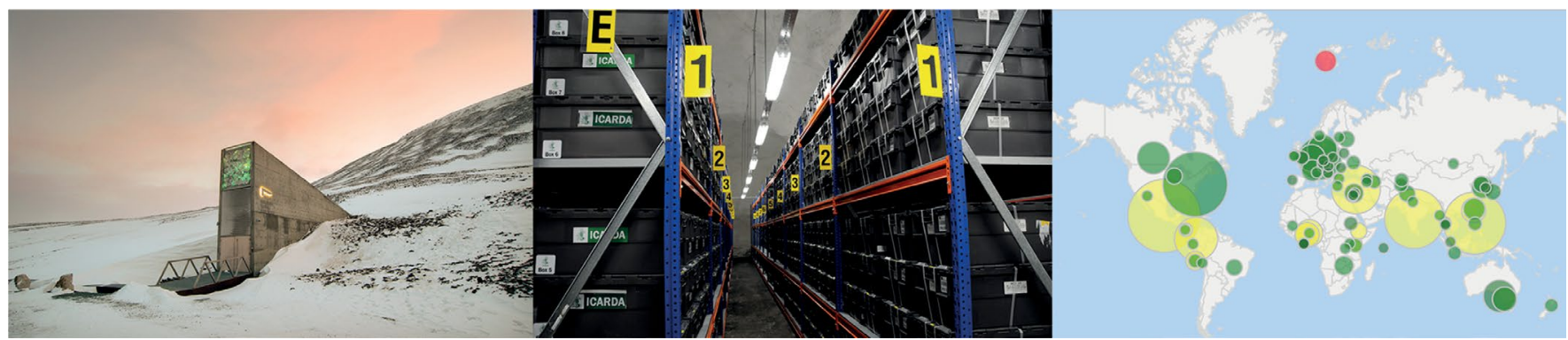

Fig. 2 | The Seed Vault collections. The entrance of the Svalbard Global Seed Vault, inside one of the storage chambers (with ICARDA boxes on the left-hand-side of the picture) and map displaying geographical location of depositor genebanks, with the size of dots corresponding to the size of safety duplicate holding in the Seed Vault. Yellow circles indicate CGIAR genebanks, and green circles indicate national and other genebanks with safety duplicates in the Seed Vault. Images adapted from the Global Crop Diversity Trust.

ICARDA genebank alone exceeds 10,000 samples per year ${ }^{37}$, with requests coming from NAROs and advanced research institutions worldwide.

The physical infrastructure of the ICARDA genebank in Tel Hadia, Syria, remained intact at least until September 2015, after which access has been denied to ICARDA local staff. ICARDA did remote monitoring of the genebank premises until April 2017. Since then, ICARDA staff have been prevented from monitoring, and no information about the state of the genebank collection is available. The premises have been occupied by at least two armed groups. If the genebank is physically intact, the viability of the seed is likely to have been affected by frequent and long power cuts. The routine operations and particularly the distribution of seed became increasingly difficult from 2012, ultimately forcing ICARDA to relocate. After careful consideration and discussion with partners, the ICARDA genebank was relocated to two sites. One of these sites in Morocco is offered by the Institut National de la Recherche Agronomique (INRA), where ICARDA now houses its collections of cultivated wheat, barley, lentil and chickpea. This location is shared with ICARDA breeders and provides an important opportunity for collaboration. The second site is situated in an existing ICARDA station in Lebanon, where optimal conditions exist for the cultivation and containment of specific crops and crop wild relatives such as faba bean, grasspea, forages and range species, as well as wild species related to wheat, barley and other crops.

\section{The Svalbard Global Seed Vault}

The Svalbard Global Seed Vault opened its doors for long-term storage of seed accessions from genebanks around the world in 2008 (refs. ${ }^{45,46}$ ). The Seed Vault has, since the early planning phase, been a collaborative project between the Norwegian government (represented by the Norwegian Ministry of Agriculture and Food (MAF)), the Nordic Genetic Resource Centre (NordGen) and the Crop Trust. The facility is located at the island Spitsbergen in the Arctic archipelago Svalbard. The archipelago is subject to the Svalbard Treaty from 1920, which recognizes Norway's sovereignty while at the same time ensures the right of other Treaty nations to enter and use natural resources. The Svalbard Treaty also ensures that the archipelago remains demilitarized. The Seed Vault is carved out of a mountain with deep permafrost, and the storage chambers are found at the end of a 120-m-long tunnel. The facility is located $130 \mathrm{~m}$ above the sea level, well above the worst-case scenarios for climate change-induced sea level rise. The facility has a high security entrance system and concrete reinforced walls, and only opens for deposits for 2-3 days twice a year. In 2019, the Seed Vault underwent an upgrade, making the entrance completely waterproof in order to withstand the effects of the slowly melting permafrost at the surface. The conditions inside the storage halls are dry and cold $\left(-18^{\circ} \mathrm{C}\right)$, in accordance with the FAO genebank standards for long-term conservation of seeds ${ }^{40}$. The seeds themselves are stored in sealed aluminium foil pouches inside deposit boxes (Fig. 2).

The terms and conditions for use of the Seed Vault are laid out in the standard deposit agreement ${ }^{46}$. The main criteria determining which accessions can be safety duplicated are that: (1) accessions are PGRFA (in order to restrict the mandate to food and forage crops and their genepools); (2) accessions have not already been deposited by another genebank (in order to avoid identical seed accessions being duplicated more than once in the Seed Vault); and (3) depositing institutes facilitate access to the accessions to users "in compliance with national laws and applicable international treaties" 46 , which for Plant Treaty members means according to the MLS. It remains the depositor's responsibility to monitor the viability of the original samples and to regenerate and send fresh new duplicates to Svalbard. On the side of the Seed Vault and its responsible authority, the deposit agreement guarantees safe and secure storage under the internationally agreed standard temperature condition of $-18{ }^{\circ} \mathrm{C}$. There is no transfer of ownership of the safety duplicates; the seeds at Svalbard cannot be distributed to anyone besides the institution that has deposited and signed the deposit agreement.

The operation of the Seed Vault is handled on a day-to-day basis by NordGen. The funding for the operation of the Seed Vault is provided by the Norwegian Government and the Crop Trust, with a small financial contribution from NordGen.

The ICARDA genebank, the Seed Vault back-up storage and the legal framework of the MLS, under which the ICARDA accessions are available to users, illustrates the necessary multi-layering of the global ex situ conservation system anno 2020. The case of the safety duplication, retrieval and regeneration of the collections under ICARDA's management in the face of war exemplifies what is possible when such layering, effective collaboration and donor support are in place.

\section{Lessons from rebuilding the ICARDA collection}

The reconstitution of the ICARDA collection has in many ways been a test of the resilience of the international ex situ system that ICARDA and the Seed Vault are parts of. The experience thus constitutes a unique learning experience also for other genebanks and institutions in the system.

Deposit at the Seed Vault is specified in the Crop Trust performance targets (Table 1) and is standard practice for all CGIAR centres managing seed collections. In the case of ICARDA, the freshest seed and the largest number of safety duplicated accessions are at the Seed Vault. Alternative safety duplicates are of seed of varying ages dispersed among multiple host institutes, depending on the crop, under a variety of legal agreements. During the Syrian war, ICARDA experienced a calamity, and given that the entire collection needed to be restituted, it was obvious for ICARDA to pursue the option of bulk retrieval of fresh seed from the Seed Vault. 
The number of safety duplicated seed per packet is relatively small, representing the genetic composition of the original accession but inadequate for distribution. Hence, the return of the accessions to ICARDA in Lebanon and Morocco necessitates several cycles of seed regeneration that will continue up to 2030 (or longer depending on funding) in order to reconstruct the entire collection and to be able to continue supplying seeds to requestors around the world. In technical terms, the reconstruction of a multi-crop collection of more than 100,000 accessions is a major undertaking, necessitating amplified funding for more than 10 years. While cultivated cereals are relatively easy to regenerate in large numbers (thousands of accessions), species requiring isolation or special conditions cannot be regenerated in bulk. Systems and facilities need to be in place for seed drying, cleaning, counting, weighing and packing, regular viability monitoring, health testing and distribution. Field sites, plastic houses and isolation cages are needed to multiply up seed for distribution and to regenerate seed lots that show declining viability. Environmental conditions must be appropriate to avoid genetic drift or worse. Irrigation must be provided if needed, and facilities for threshing and drying as well as controls must be in place to capture seeds if shattering is occurring and to cater for the reproductive biology of individual crop species, which may involve controlled or insect pollination. ICARDA-Lebanon genebank now offers one the world's largest facilities for the regeneration of wild- and cross-pollinated species, with 40 isolation cages used for self-compatible, cross-pollinated species (faba bean and grasspea) and 200 isolation cages used for self-incompatible, cross-pollinated species, which employ bumble bees to enhance pollination.

Prioritization and phased planning are essential to maintain the integrity of the collection, and contingency plans are important given that in any one year, costs or funding may be suboptimal. Furthermore, regenerating in bulk requires increased capacity in irrigation, threshing, temporary storage, seed health testing, seed processing, viability testing, drying and packing, and so on. While initiating processes afresh provides an opportunity to do things better, it is also likely to result in both temporary and permanent changes to standard operating procedures (SOPs), which must be documented if future managers are to understand the vulnerabilities inherent in the collections and associated data. For instance, faster methods to test initial viability may be instigated, involving the use of representative samples rather than testing all harvested accessions or one replicate rather than two. Either will necessitate changes not only in the SOP, but also in the management and interpretation of data that must be made clearly and permanently evident.

Standards demand a combination of timely harvesting and seed processing; customized treatments in cleaning, testing and drying; and precise weighing, counting and sealing in air-tight containers. Mistakes at any point have major consequences that may only be revealed years later when the packet is opened and an attempt is made to germinate the seeds. Hence the treatment of seed before reaching Svalbard is as critical as the conditions provided therein.

In addition to the technical lessons learned, the rescue of the ICARDA genebank collection also offers institutional and policy insights. First and foremost, the story shows that international cooperation is essential for safeguarding genetic resources and crop diversity for public use by future generations. The international collaboration behind such a successful rescue operation is underpinned by the legal framework provided by the FAO's CGRFA and the Plant Treaty.

The FAO bodies were important in several ways: firstly, by welcoming Norway's proposal to take on the task of constructing the Seed Vault in the first place ${ }^{45,47}$; secondly, in providing ICARDA, despite its relocation, the legal recognition to continue functioning as an international genebank to conserve and give access to "global common goods"38; and thirdly, providing the basis for ICARDA,
CGIAR and the Crop Trust to seek funding to reconstruct its facilities and regenerate its collections.

Not only continued but increased support for ICARDA during the relocation was critical. Its international status and years of solid partnership helped to provide the confidence required to both host countries and donors that ICARDA would continue to operate successfully and sustainably in its new structure and locations. The construction of the new facilities and the costs of the regeneration were borne by national institutes, CGIAR System donors, Crop Trust and bilateral donors such as the European Commission, and depended on flexibility in budgeting, planning and oversight.

\section{Conclusion}

A hundred years after Nicolai Vavilov established the world's first genebank and 50 years after the FAO sounded the alarm about the loss of genetic resources, this biodiversity of such fundamental importance for humankind remains endangered and in need of concerted conservation efforts, both in situ and ex situ.

ICARDA manages one of the world's most important genebanks, holding a large number of unique seed accessions from the region where agriculture first evolved and harbouring traits of importance for making crops more resilient in the face of climate change, pests and diseases, and adverse weather conditions. But as the case of ICARDA illustrates, genebanks are also vulnerable to natural and human-caused disasters, and their resilience relies on an increasingly strengthened and experienced multilateral system of governance, science, financial support and collaboration.

The terrible war in Syria has complex social, economic and political causes, and cannot be reduced to a resource scarcity issue. At the same time, it is evident that the negative effects on food production due to mismanagement of the natural resource base-depletion of groundwater and desertification as well as the impacts of economic policies to phase out of subsidies to agriculture coinciding with a prolonged drought in the years 2006-2010-and peaking global food prices was part of the dangerous mix leading to $\operatorname{war}^{22,48}$. The violent control over food supply during the war has further exacerbated the food insecurity situation, and peacebuilding efforts in fragile states such as Syria cannot succeed unless they also include efforts to build more sustainable agri-food systems ${ }^{24}$.

Agri-food systems are commonly conceptualized in terms of the activities and institutions involved in the production, processing, distribution and consumption of food-from farm to fork. Crop diversity and plant breeding is foundational for all of this, and efforts to build sustainable and socially equitable agri-food systems rely on having a resilient system for conservation and access to genetic resources.

The story about the rebuilding of the ICARDA collection makes evident the facets of the existing global ex situ system. One may say that the Plant Treaty, the FAO genebank standards, Genesys, Crop Trust monitoring and financing system represent the 'software' of this global system, and the Svalbard Global Seed Vault, the Article 15 collections and the public genebanks in the member countries are the 'hardware'.

\section{Received: 1 July 2020; Accepted: 8 October 2020;}

\section{References}

1. Frankel, O. \& Bennett, E. Genetic Resources in Plants: Their Exploration and Conservation (Blackwell Scientific Publications, 1970).

2. Hufford, M. B., Berny Mier y Teran, J. C. \& Gepts, P. Crop biodiversity: an unfinished magnum opus of nature. Annu. Rev. Plant Biol. 70, 727-751 (2019).

3. Fowler, C. \& Hodgkin, T. Plant genetic resources for food and agriculture: Assessing global availability. Annu. Rev. Environ. Resour. 29, 143-179 (2004).

4. Godfray, H. C. J. et al. Food security: the challenge of feeding 9 billion people. Science 327, 812-818 (2010).

5. Willett, W. et al. Food in the Anthropocene: the EAT-Lancet Commission on healthy diets from sustainable food systems. The Lancet 393, 447-492 (2019). 
6. Crosby, A. W. Ecological Imperialism: the Biological Expansion of Europe, 900-1900 (Cambridge Univ. Press, 2004).

7. Diamond, J. \& Bellwood, P. Farmers and their languages: the first expansions. Science 300, 597-603 (2003).

8. Harlan, J. R. Crops and Man (American Society of Agronomy, 1975).

9. Larson, G. et al. Current perspectives and the future of domestication studies. Proc. Natl Acad. Sci. USA 111, 6139-6146 (2014).

10. Zohary, D. \& Hopf, M. Domestication of Plants in the Old World: the Origin and Spread of Cultivated Plants in West Asia, Europe and the Nile Valley (Oxford Univ. Press, 2000).

11. Harlan, J. R. Our vanishing genetic resources. Science 188, 617-621 (1975).

12. Aichi biodiversity targets. Convention on Biological Diversity https://www.cbd. int/sp/targets/ (2010).

13. International Treaty on Plant Genetic Resources for Food and Agriculture. FAO http://www.planttreaty.org/ (2001).

14. The Sustainable Development Goals. United Nations https://www.un.org/ sustainabledevelopment/ (2015).

15. Amri, A. ICARDA'S Genebank Resources and Activities: A Vital Tool in Ensuring a Food-Secure Future for Dryland Communities (ICARDA, 2015).

16. Khoury, C. K. et al. Origins of food crops connect countries worldwide. Proc. R. Soc. B 283, 20160792 (2016).

17. Mbow, C. et al. in Climate Change and Land: an IPCC Special Report on Climate Change, Desertification, Land Degradation, Sustainable Land Management, Food Security and Greenhouse Gas Fluxes in Terrestrial Ecosystems Ch. 5 (IPCC, 2019).

18. Porter, J. R. et al. in Climate Change 2014: Impacts, Adaptation, and Vulnerability (Field, C. B. et al.) 485-533 (Cambridge Univ. Press, 2014)

19. Kelley, C. P., Mohtadi, S., Cane, M. A., Seager, R. \& Kushnir, Y. Climate change in the Fertile Crescent and implications of the recent Syrian drought. Proc. Natl Acad. Sci. USA 112, 3241-3246 (2015).

20. Werrell, C. E., Femia, F. \& Sternberg, T. Did we see it coming?: State fragility, climate vulnerability, and the uprisings in Syria and Egypt. SAIS Rev. Int. Aff. 35, 29-46 (2015)

21. Gilmore, E. A., Risi, L. H., Tennant, E. \& Buhaug, H. Bridging research and policy on climate change and conflict. Curr. Clim. Change Rep. 4, 313-319 (2018)

22. De Châtel, F. The role of drought and climate change in the Syrian uprising: untangling the triggers of the revolution. Middle East. Stud. 50, 521-535 (2014).

23. Brück, T. \& d'Errico, M. Food security and violent conflict: introduction to the special issue. World Dev. 117, 167-171 (2019).

24. FAO, IFAD, UNICEF, WFP \& WHO. The State of Food Security and Nutrition in the World 2017. Building Resilience for Peace and Food Security (FAO Rome, 2017).

25. Kanfash, M. \& Al-Jasem, A. Syrians are Watching Their Crops Burn. These Crimes of Starvation Must End. The Guardian https://bit.ly/311Te3e (2019).

26. Sengupta, S. How a Seed Bank, Almost Lost in Syria's war, Could Help Feed a Warming Planet. The New York Times https://nyti.ms/2SS8gE0 (2017).

27. ICARDA receives gregor mendel innovation prize for ensuring safekeeping of its genebank collection. ICARDA https://bit.ly/370RVFj (2015).

28. Alexanyan, S. M. \& Krivchenko, V. I. Vavilov Institute scientists heroically preserve world plant genetic resources collections during World War II siege of Leningrad. Diversity 7, 10-13 (1991).

29. Tracking Progress on Food and Agriculture-related SDG Indicators (FAO, 2020) http://www.fao.org/sdg-progress-report/en/\#sdg-2

30. The State of the World's Biodiversity for Food and Agriculture (eds J. Bélanger, J. \& D. Pilling, D.) (FAO Commission on Genetic Resources for Food and Agriculture Assessments, 2019)

31. International Treaty on Plant Genetic Resources for Food and Agriculture. FAO http://www.fao.org/plant-treaty/countries/en (2020).

32. Esquinas-Alcázar, J. T., Frison, C. \& López, F. in Plant Genetic Resources and Food Security (eds Frison, C. et al.) 35-58 (Routledge, 2012).
33. Andersen, R. in Routledge Handbook of Agricultural Biodiversity (eds Hunter, D. et al.) 449-470 (Routledge, 2017).

34. Toledo, Á. \& Manzella, D. The Role of the International Treaty on Plant Genetic Resources for Food and Agriculture (FAO, 2012).

35. GRIN-Global: a data management tool for all genebanks. Crop Trust https://www.croptrust.org/blog/ grin-global-a-data-management-tool-for-all-genebanks/ (2020).

36. Seed portal of the Svalbard global seed vault. NordGen https://www.nordgen. org/sgsv (2020).

37. CGIAR Genebank Platform 2018 Annual Report (Genebank Platform, 2019).

38. Noriega, I. L. et al. CGIAR Operations under the Plant Treaty Framework. Crop Sci. 59, 819-832 (2019).

39. The Second Report on the State of the World's Plant Genetic Resources (FAO, 2010).

40. Genebank Standards for Plant Genetic Resources for Food and Agriculture (FAO, 2014).

41. CGIAR. Crop Trust CGIAR Genebank Platform https://www.genebanks.org/ (2020)

42. van Hintum, T., Menting, F. \& van Strien, E. Quality indicators for passport data in ex situ genebanks. Plant Genet. Resour. 9, 478-485 (2011).

43. Wepage of the global crop diversity trust. Crop Trust https://www.croptrust. org/ (2020).

44. Bari, A. et al. Focused identification of germplasm strategy (FIGS) detects wheat stem rust resistance linked to environmental variables. Genet. Resour. Crop Ev. 59, 1465-1481 (2012).

45. Westengen, O. T., Jeppson, S. \& Guarino, L. Global ex-situ crop diversity conservation and the Svalbard global seed vault: assessing the current status. PLoS ONE 8, e64146 (2013).

46. Standard Agreement between the Depositor and the Norwegian Ministry of Agriculture and Food (MAF, 2020).

47. Qvenild, M. Svalbard Global Seed Vault: a 'Noah's Ark' for the world's seeds. Dev. Pract. 18, 110-116 (2008)

48. Lagi, M., Bertrand, K. Z. \& Bar-Yam, Y. The food crises and political instability in North Africa and the Middle East. SSRN https://doi.org/10.2139/ ssrn.1910031 (2011)

\section{Acknowledgements}

We thank M. Major and L. Marshall for preparing the artwork. Work for this Perspective performed by O.T.W. was supported by the Research Council of Norway (grant no. RCN-274519), in the research project Suitable Seeds for Food Security in Fragile States, led by the Fridtjof Nansen Institute, Norway. We also thank project colleagues R. Andersen, K. Rosendal, P. W. Skedsmo, K. Adhikari and A. Ramana for their comments on the manuscript.

\section{Author contributions}

O.T.W. and C.L. conceived and wrote the manuscript. M.Y., A.A. and Å.A. contributed to the manuscript.

\section{Competing interests}

The authors declare no competing interests.

\section{Additional information}

\section{Correspondence should be addressed to O.T.W.}

Peer review information Nature Plants thanks John Dickie and Peter Raven for their contribution to the peer review of this work.

Reprints and permissions information is available at www.nature.com/reprints.

Publisher's note Springer Nature remains neutral with regard to jurisdictional claims in published maps and institutional affiliations.

(C) Springer Nature Limited 2020 